\title{
Vertical structure of currents in the vicinity of the Iceland-Scotland Ridge
}

\author{
C. Carollo ${ }^{1}$, I. Astin ${ }^{2}$, and J. Graff ${ }^{3}$ \\ ${ }^{1}$ The University of Chicago, Dept of the Geophysical Sciences, Chicago, IL 60637, USA \\ ${ }^{2}$ The University of Bath, Dept of Electronic and Electrical Engineering, Bath, BA2 7AY, UK \\ ${ }^{3}$ British Maritime Technology Ltd., Teddington, Middlesex, TW14 8LZ, UK
}

Received: 20 May 2004 - Revised: 16 March 2005 - Accepted: 23 May 2005 - Published: 15 September 2005

\begin{abstract}
An analysis of current profiles carried out on moored Acoustic Doppler Current Profiler data sets recorded during the Variability of Exchanges In the Northern Seas project is presented here for several locations in three sections in the vicinity of the Iceland-Scotland Ridge: (1) north of the Faroes, (2) in the Faroe-Bank Channel and (3) in the Faroe-Shetland Channel. Total currents have been decomposed into three components, namely the mean residual flow, tide and surge. The mean residual flow is found to be dominant. Results for the major tidal constituents $\left(M_{2}, S_{2}, N_{2}\right.$, $O_{1}$ and $K_{1}$ ) are shown and discussed. It is found that the predominant tidal harmonic $M_{2}$ becomes steered through depth to align with the bottom topography. The mean residual flow is found to be generally larger than the surge, particularly in the Faroe-Bank Channel below $500 \mathrm{~m}$ depth where it is the dominant component. Here tidal rectification, i.e. the topographic rectification of tidal currents originating in nonlinearities that rectify the oscillatory tidal motion, is identified as the process enhancing the large mean residual currents found. From the current structure, two water masses are identified in the channel: the upper slowing moving inflow water and the colder outflow water characterised by a 3-6-day periodicity. In the Faroe-Shetland Channel the flow is characterised by large tidal currents, particularly in shallow waters. Instead, north of the Faroes none of the component was identified as dominant. The results show that the variability of the current components is strongly dependent upon topography and water depth.
\end{abstract}

Keywords. Oceanography: Physical (Currents; General circulation; General or miscellaneous)

\section{Introduction}

The aim of this study is to understand the vertical and spatial variability of tidal and residual currents in three sections

Correspondence to: C. Carollo

(ccarollo@geosci.uchicago.edu) located north of the Faroe Islands, in the Faroe-Bank Channel (FBC) and in the Faroe-Shetland Channel (FSC) (Fig. 1) and to relate this to the water movement for the region.

Such an approach for the analysis of current structure through the water column is common in ocean literature (Halpern, 1976; Saunders, 1976; Halpern et al., 1977, 1978; Halpern, 1979; Brink et al., 1980; Godfrey et al., 1980; Halpern, 1980; Jones and Halpern, 1981; Pingree and Mardell, 1981; Heathershaw, 1985; Halpern, 1987a,b). The procedure generally followed is to identify (1) factors influencing current speed, (2) the effect of the wind stress on surface layers (Halpern, 1976; Jones and Halpern, 1981), (3) the vertical stratification of temperature and salinity (Halpern, 1980), and (4) the influence of the sloping topography on tidal and residual currents, particularly in areas like the shelfbreak (Pingree and Mardell, 1981). This list is by no means exhaustive but is included to illustrate the importance of considering the vertical current profiles.

The object of the study here is to identify the current components that may dominate extremes in ocean currents and to better understand their make-up. It is proved to be necessary prior to the application of the statistical analysis of extreme events to allow for a physical interpretation of the results, as shown in the companion paper.

Evidence of topographic steering and rectification for tidal currents is investigated. Previous work by Allen (1995) studies sub-tidal and tidal currents north of the Faroes in the region of the Iceland-Faroe Front showing the spatial variation of tidal currents due to the bottom topography. The semidiurnal tide is indicated be the largest in both $u$ and $v$ velocity components and can be affected by the meandering of the front. Sherwin and Jeans (1997) analyse tidal currents in the Wyville-Thomson Ridge at the southern end of the FSC section and show that three semi-diurnal components $\left(M_{2}, S_{2}\right.$ and $\left.N_{2}\right)$ dominate tidal currents (in agreement with Sherwin (1991)). Similarly Simonsen (1999) describes the semi-diurnal character that dominates tidal currents around the Faroe Islands and indicates the presence of topographical trapped waves along the Scottish and Faroe shelves. 


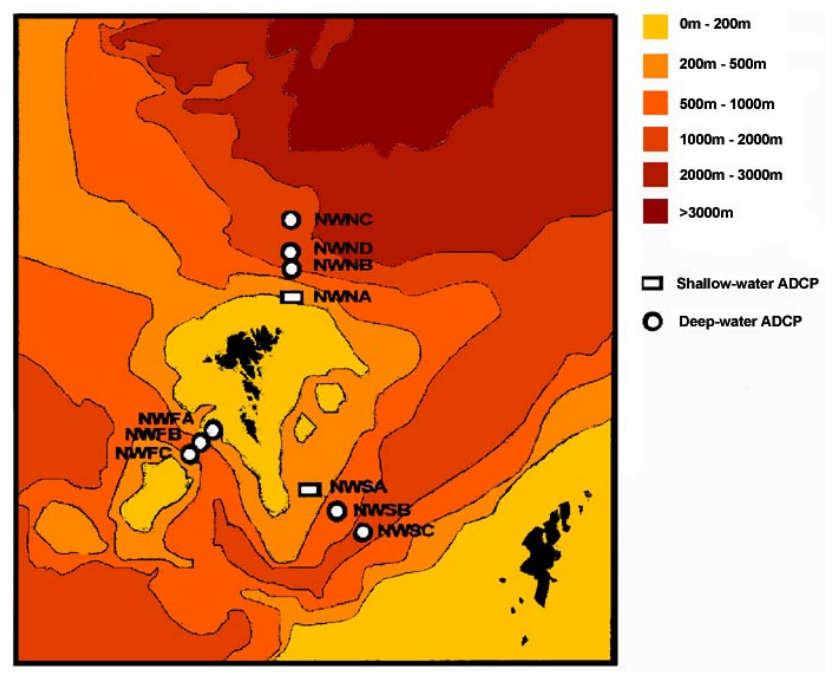

Fig. 1. VEINS deployments in sections $N$ (north of the Faroes), F (Faroe-Bank Channel), and S (Faroe-Shetland Channel) (modified from Hansen et al. (1999a)).

\section{ADCP data}

The Variability of Exchanges In the Northern Seas (VEINS) project was set up to evaluate the variability of the fluxes between the North Atlantic and the Arctic Ocean (Hansen et al., 1998; Hansen and Østerhus, 2000; Hansen et al., 2001). To achieve this, long-term upward looking Acoustic Doppler Current Profiler (ADCP) were deployed in several locations around the Faroe Islands (Hansen et al., 1999a,b).

The importance of this area lies in being the connection and the conduit for water mass exchange across the IcelandScotland Ridge.

ADCP data consist of $u$ and $v$ current velocity components averaged vertically over $10 \mathrm{~m}$ depth bins for shallow water deployments, and $25 \mathrm{~m}$ depth bins for deep water deployments and over 20 min time interval (Hansen et al., 1999a).

In the sections considered in this study upward looking ADCP were deployed at 7 standard mooring sites and 3 special ones (FA, FC and ND) (Hansen et al., 1999a) (see Fig. 1).

Measurements were taken from June 1996 to June 1999 from around 40/200 $\mathrm{m}$ down to $300 / 900 \mathrm{~m}$ depending on the sea-floor depth at each location. Details of the deployments are given in Table 1.

The recorded current data sets are not continuous in time due to missing data, especially for the near-surface bins that are most distant from the instrument. ADCP records have been quality controlled by the Faroese Fisheries Laboratory by comparing the performance of the instruments and the variation of data with time in relation to neighbouring bins. During the editing process missing data, outliers and data including large errors were flagged; bins with less than $50 \%$ valid data were rejected (Hansen et al., 1999a).
Table 1. Latitude and longitude (degrees), sea-floor depth (in meters) and number of days available for the ADCP time series recorded during the VEINS project.

\begin{tabular}{ccccc}
\hline & latitude & longitude & depth & days \\
\hline$F A$ & $6126.40 \mathrm{~N}$ & $0814.56 \mathrm{~W}$ & 718 & 71 \\
$F B$ & $6124.98 \mathrm{~N}$ & $0816.98 \mathrm{~W}$ & 816 & 362 \\
$F B$ & $6124.93 \mathrm{~N}$ & $0817.34 \mathrm{~W}$ & 818 & 71 \\
$F B$ & $6124.95 \mathrm{~N}$ & $0817.13 \mathrm{~W}$ & 815 & 273 \\
$F C$ & $6123.60 \mathrm{~N}$ & $0818.95 \mathrm{~W}$ & 836 & 71 \\
$N A$ & $6242.31 \mathrm{~N}$ & $0605.17 \mathrm{~W}$ & 300 & 359 \\
$N A$ & $6242.17 \mathrm{~N}$ & $0605.04 \mathrm{~W}$ & 297 & 360 \\
$N B$ & $6254.81 \mathrm{~N}$ & $0604.95 \mathrm{~W}$ & 907 & 365 \\
$N B$ & $6255.15 \mathrm{~N}$ & $0604.84 \mathrm{~W}$ & 961 & 349 \\
$N C$ & $6316.42 \mathrm{~N}$ & $0606.60 \mathrm{~W}$ & 1733 & 364 \\
$N C$ & $6315.94 \mathrm{~N}$ & $0606.29 \mathrm{~W}$ & 1728 & 349 \\
$N D$ & $6257.54 \mathrm{~N}$ & $0605.06 \mathrm{~W}$ & 1283 & 214 \\
$S A$ & $6100.13 \mathrm{~N}$ & $0550.61 \mathrm{~W}$ & 295 & 218 \\
$S B$ & $6046.93 \mathrm{~N}$ & $0518.48 \mathrm{~W}$ & 782 & 271 \\
$S C$ & $6034.03 \mathrm{~N}$ & $0446.10 \mathrm{~W}$ & 1068 & 318 \\
$S C$ & $6033.98 \mathrm{~N}$ & $0446.10 \mathrm{~W}$ & 1076 & 271 \\
\hline
\end{tabular}

\subsection{Section N: north of the Faroes}

North of the Faroe Islands, where the Iceland Faroe Front (IFF) separates warm water masses of Atlantic origin from colder waters produced in the Arctic region, three quasipermanent mooring sites (NC, NB, NA) plus a shorter deployment at a site ND (between NB and NC) (Hansen et al., 1999a), were located on a north-south section (Fig. 1), which traverses the flow (Hansen et al., 1999b). From north to south there is a steep decrease in the bottom depth (from $1700 \mathrm{~m}$ to $300 \mathrm{~m}$ ), i.e. NA is located in shallow waters.

The deployments NA, NB, ND and NC traverse the Faroe Current as it flows eastward (Hansen et al., 1999b). This current is a jet with its core over the slope, where maximum velocity is recorded (Hansen et al., 1998).

This area is characterised by the presence of meanders and eddies of 30-50-km scale that move eastward with the front itself (Hansen and Østerhus, 2000).

\subsection{Section F: the Faroe-Bank Channel}

In the $\mathrm{FBC}$ one quasi-permanent mooring site (FB) plus two shorter deployments (FA and FC) were located on a southwest section across the channel (Fig. 1) (Hansen et al., 1999a). At these sites deep-water instruments were deployed (sea-floor depth around $800 \mathrm{~m}$ ).

This channel, which separates the Faroe Plateau from the Faroe Bank, is about $20 \mathrm{~km}$ wide, has sill depth of about $840 \mathrm{~m}$, and is the deepest passage of the Ridge. It is, therefore, the main outlet of cold waters from the Nordic Seas that dominate the deepest 200/300 m of this channel (Hansen et al., 1998; Østerhus et al., 1999).

Different water masses are found in the channel as extensively described in Hansen and Østerhus (2000): 
(1) Modified North Atlantic Water (MNAW) located from the surface to about $250 \mathrm{~m}$, (2) intermediate water, from $250 \mathrm{~m}$ to $550 \mathrm{~m}$, is a mixture of the two water masses from above and below, (3) bottom water made up of Norwegian Sea Arctic Intermediate Water (NSAIW) and Norwegian Sea Deep Water (NSDW) (Østerhus et al., 1999).

At the central site (FB) cold waters flow northwestward in a current with average velocities exceeding $1 \mathrm{~m} \mathrm{~s}^{-1}$ in its core, centered about $120 \mathrm{~m}$ above the bottom (Østerhus et al., 1999). In the channel the flow is strongly steered by the bottom topography; the mean direction is, in fact, $135 / 315^{\circ}$ (Saunders, 1990).

\subsection{Section S: The Faroe-Shetland Channel}

In the southwestern part of the FSC three mooring sites (SA, SB and SC) were located on a southeast section (Fig. 1). The deployment at site SA is a shallow water one; at sites SB and SC deep water instruments were used (Hansen et al., 1999a). There is a steep increase in the sea-floor depth from SA to SC along the section from 295 to $1076 \mathrm{~m}$.

This channel separates the Faroe Plateau from the British Isles. Sea-floor depth is about $1500 \mathrm{~m}$ on the northern end, with a minimum of $1000 \mathrm{~m}$, and is just over $600 \mathrm{~m}$ on its southern part where it is blocked by the Wyville-Thomson Ridge (Sherwin et al., 1999). Bathymetry dominates current dynamics in this channel, which is one of the most important passage of the region for the overflow.

The water column is characterised by the presence of: (1) two different surface water masses, North Atlantic Water (NAW) and Modified North Atlantic Water (MNAW), (2) two intermediate water masses Arctic Intermediate Water (AIW) from $400 \mathrm{~m}$ to $600 \mathrm{~m}$, and Norwegian Sea Arctic Intermediate Water (NSAIW) from $600 \mathrm{~m}$ to $800 \mathrm{~m}$, (3) a bottom water mass known as Faroe-Shetland Channel Bottom Water (FSCBW) that is a mix of Norwegian Sea Deep Water (NSDW) and NSAIW in different percentages (Sherwin et al., 1999). Details can be found in Hansen and Østerhus (2000).

The speed of the along-shore current on the Shetland side of the channel increases off-shore (from $10 \mathrm{~cm} \mathrm{~s}^{-1}$ over $200 \mathrm{~m}$ depth to $20 \mathrm{~cm} \mathrm{~s}^{-1}$ over $500 \mathrm{~m}$ depth) (Hansen and Østerhus, 2000).

\section{Methodology}

\subsection{Justification for the paradigm of the methodology}

It is usual to analyse $u$ and $v$ velocity components separately through a tidal analysis. The difference between raw data and tidal currents gives the non-tidal flow that subsequently is filtered to remove long-term trend. The normal procedure (Pugh, 1987) is to make a harmonic tidal analysis of these raw data usually specifying harmonics $\leq 1$ cycle per day (cpd). Following this methodology, long period variations influenced by meteorological effects are not considered and are resolved as a mean residual offset.
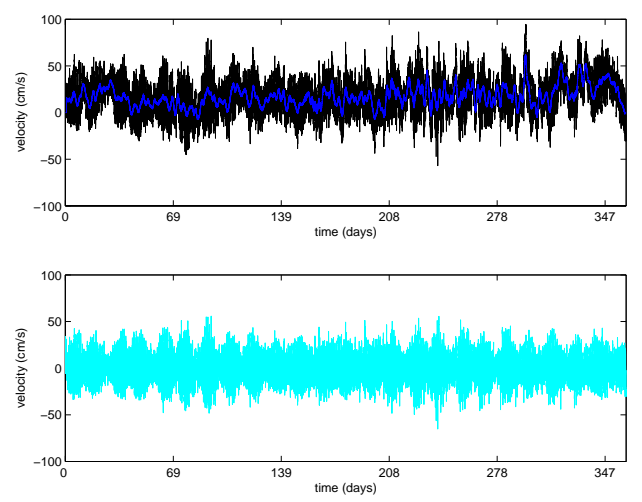

Fig. 2. Linearly interpolated raw data (black), low-passed data (blue) and high frequency data (cyan) are shown for $u$ component at location NA, $170 \mathrm{~m}$ depth.

However, to avoid mistakes in the interpretation of the results a better approach is to pre-filter, i.e. use the filter before applying the harmonic analysis as proposed by Graff (1986). Serious anomalies can arise in applying conventional tidal harmonic analysis in cases where residual drift is in line with the dominant tidal current and is of similar amplitude. For example, in the case of a semi-diurnal dominant current with energy peaks at $2 \mathrm{cpd}$ it becomes rectified into a pseudo diurnal current $(1 \mathrm{cpd})$ response that contributes to the resolution of pseudo diurnal tidal harmonics that can give a seriously false representation of the tidal regime. In this way a "cleaner" time series can then be processed using a tidal harmonic analysis (Graff, 1986) to separate out tide and surge component.

This methodology was followed after the application of the standard methodology to the time-series collected in the FBC showed that the semi-diurnal harmonics reduced drastically at about $500 \mathrm{~m}$ depth thus suggesting a possible interaction between the mean flow and the tidal components. It was found that diurnal harmonics increased in value.

\subsection{Filtering}

Raw data (divided into $v$ and $u$ component) were pre-filtered using a 39-h centrally averaging Doodson X0 filter with a cutoff of $1 \mathrm{cpd}$ to separate out low frequency data (less than $1 \mathrm{cpd}$ ) and high frequency data (tidal and surge component) (Graff, 1986). Any gaps present in the data were interpolated.

The high frequency data (Fig. 2) were then subjected to a tidal analysis to resolve the data further into tidal and nontidal (surge) components (Fig. 3).

\subsection{Tidal Analysis}

Tides can be expressed as a Fourier sum of tidal harmonic constituents in the form

$X(t)=A_{0}+\sum a_{N} \cos \left(\omega_{N} t-\phi_{N}\right)$,

where $A_{0}$ is the mean flow/level and $a_{N}$ is the amplitude of the tidal constituent, $\omega_{N}$ is the angular frequency, and $\phi_{N}$ 

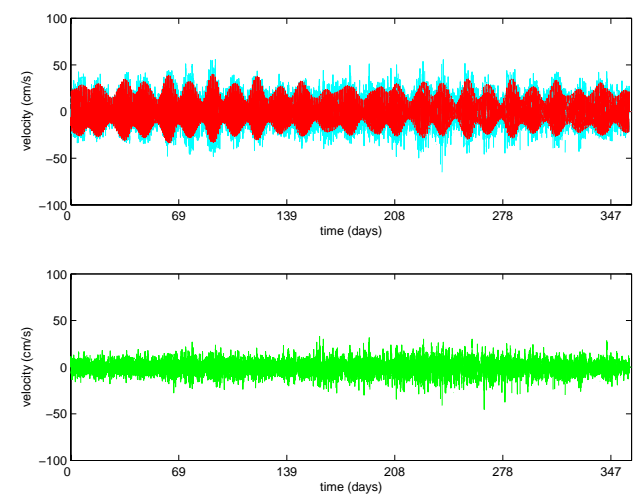

Fig. 3. High frequency data (cyan), tidal data (red) and surge data (green) are shown for $u$ component at location NA, $170 \mathrm{~m}$ depth.

is a phase lag relative to the Equilibrium Tide. Each tidal harmonic has a specific physical origin with dominant ones being of lunar $\left(M_{2}\right)$ and solar $\left(S_{2}\right)$ semi-diurnal form.

The aim of a tidal analysis is to resolve a sufficient number of tidal harmonics to describe the tidal regime at the place of observation (Pugh, 1987). N depends upon the length and quality of the observed data and complexity of tidal regime (Pugh, 1987).

The POL/PSMSL (Proudman Oceanographic Laboratory/Permanent Service for Mean Sea Level) Tidal Analysis Software Kit 2000 (Bell et al., 2000) was used for this purpose.

Due to the different length of the time-series available 3 sets of tidal constituents were specified. The first set appropriate to monthly data sets was made up of 27 major constituents and 8 related constituents. The second set appropriate to data sets greater than 6 months was made up of 55 major constituents plus 2 related constituents. The third set, suitable for the analysis of one year or longer data sets, was made up of 58 major constituents including seasonal dependence for $M_{2}$ (Bell et al., 2000). Following the above methodology the long period variations with frequency $<1 \mathrm{cpd}$ which are influenced by meteorological effects were incorporated into the low frequency data and not considered in the tidal analysis.

From these analyses only the largest 5 tidal constituents were selected and studied: three semi-diurnal harmonics $\left(M_{2}, S_{2}\right.$ and $\left.N_{2}\right)$ and two diurnal harmonics $\left(O_{1}\right.$ and $\left.K_{1}\right)$.

The matlab functions used to convert amplitude and phase into ellipse parameters and to plot the results were created by $\mathrm{Xu}(2000)$.

\section{Results}

\subsection{Section $\mathrm{N}$}

\subsubsection{Tidal Component}

The harmonic constituent $M_{2}$ (Fig. 4) was found to be the most important in the section north of the Faroes. The value of the semi-major axis for this constituent generally decreases at corresponding levels from location NA to location NC (Fig. 4), i.e. with increasing bottom depth, due to the presence of an amphidrome north of NC. The largest values were found at around $200 \mathrm{~m}$ depth $\left(18.834 \mathrm{~cm} \mathrm{~s}^{-1}\right.$ at $213 \mathrm{~m}$ location NA) where the Faroe Current has its core (Hansen et al., 1998), while minimum values were found at about $300 \mathrm{~m}$ depth at location NC (Fig. 4). The same spatial and vertical variations were found for the other two semi-diurnal tidal harmonics $S_{2}$ and $N_{2}$ (Fig. 4). They are smaller than $M_{2}$ at all depths. The diurnal constituents are generally smaller than the semi-diurnal ones and they do not vary greatly with depth (Fig. 4).

\subsubsection{Mean Residual Flow and Surge Component}

The amplitude of the mean residual flow decreases with depth (Fig. 5). At location NA the direction of the mean residual flow $\left(100 / 150^{\circ}\right)$ is very stable through time and depth with periodicity of 3 to 6 days. Peaks of about $60 / 70 \mathrm{~cm} \mathrm{~s}^{-1}$ were found in surface waters while peaks of $40 / 50 \mathrm{~cm} \mathrm{~s}^{-1}$ characterise bottom waters. At NB, instead, it is stable $\left(100 / 150^{\circ}\right)$ only in the surfacemost measurements, but not all year round. In deep waters there is a strong directionality toward $300^{\circ}$ in some months again with a periodicity of 3 to 6 days (Fig. 6). At location NC the directionality $\left(200^{\circ}\right)$ is less stable.

In near-surface waters the surge component is smaller than the mean residual flow. Instead at the bottom it is generally larger or of the same amplitude (Fig. 5). This component shows a preferred direction of flow between $60 / 90^{\circ}-$ $240 / 270^{\circ}$ from 50 to $100 \mathrm{~m}$ at site NA. The surge does not show any preferred direction at locations NB and NC. Peaks of about $120 / 140 \mathrm{~cm} \mathrm{~s}^{-1}$ were recorded in surface waters and of about $30 / 40 \mathrm{~cm} \mathrm{~s}^{-1}$ near the bottom (Fig. 5).

\subsection{Section $\mathrm{F}$}

\subsubsection{Tidal component}

$M_{2}$ was found to be the dominant tidal harmonic in the FBC deployments (Fig. 7). The value of the semi-major axis for this constituent generally decreases rapidly with depth and it is does not show great spatial variation at corresponding levels. Largest values were therefore found in the surfacemost measurements. Different behaviour is shown by the other two semi-diurnal tidal constituents (Fig. 7). In fact, for these, the largest values were found around $350 / 400 \mathrm{~m}$ or even deeper, though in magnitude smaller than the ones observed for $M_{2}$. This means that while the energy of $M_{2}$ decreases through depth it does not vary greatly for $S_{2}$ and $N_{2}$. The inclination of the semi-major axis for the semi-diurnal constituents changes abruptly at around 500/600 m (Fig. 7) to align with topography providing evidence of topographic steering of tidal flows.

The diurnal constituents increase with depth from the surface to about $550 / 650 \mathrm{~m}$ and then decreases in deep waters 
$N A$
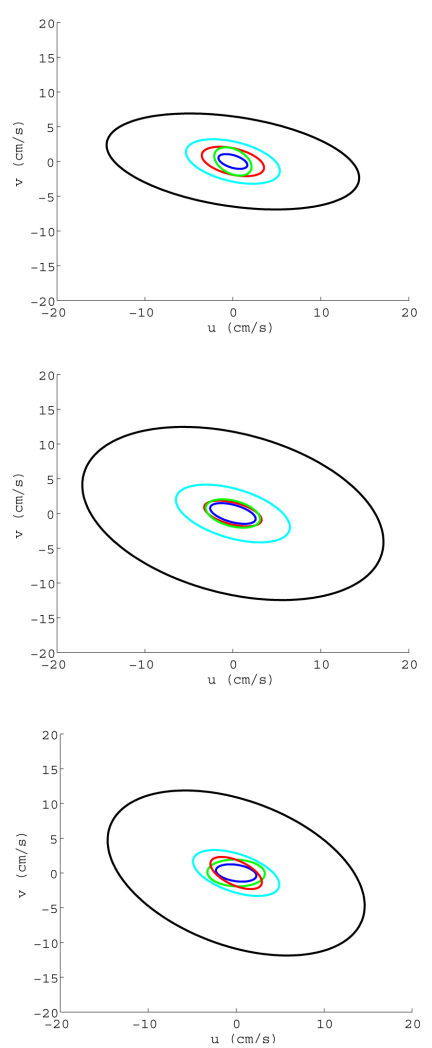

$N B$
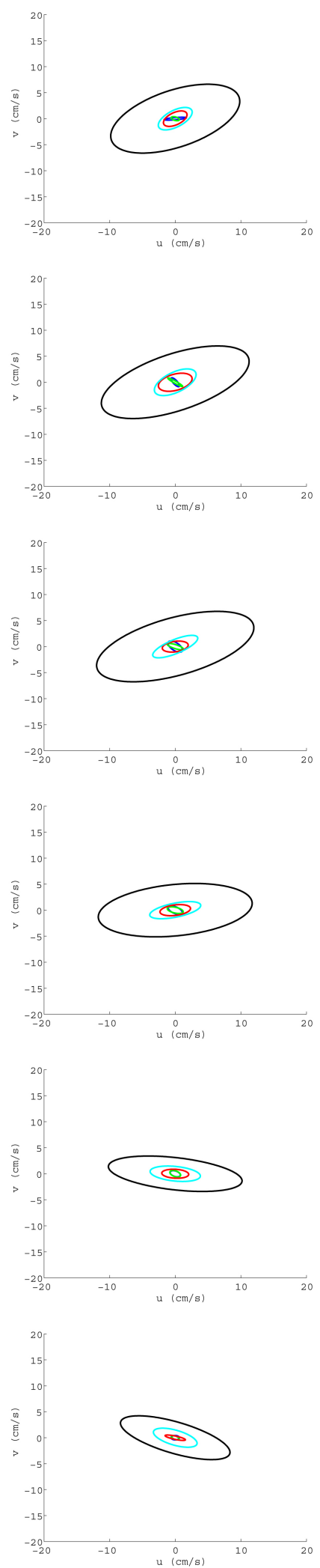

$N C$
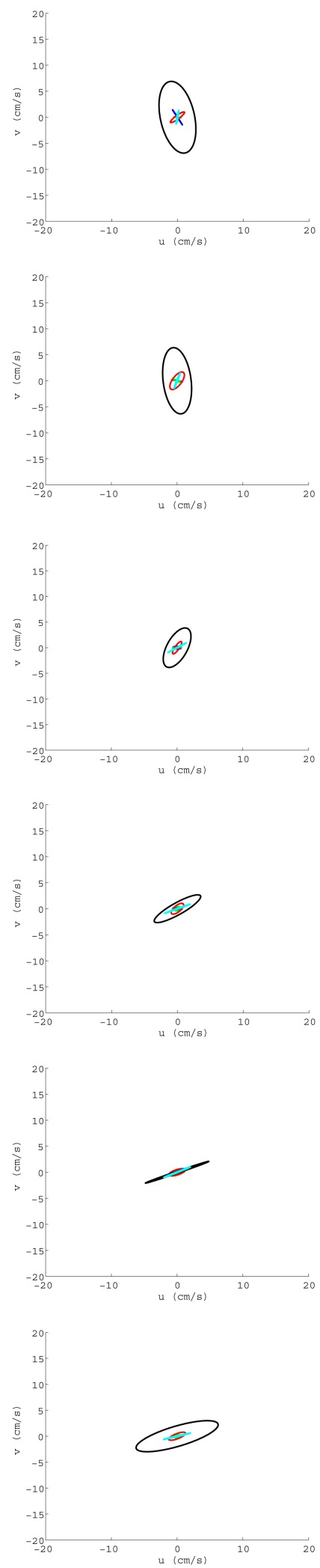

Fig. 4. Variation of tidal constituents ( $M_{2}$ black, $S_{2}$ cyan, $N_{2}$ red, $O_{1}$ blue and $K_{1}$ green) with depth (from top to bottom at about 220, 320, $420,520,620$, and $720 \mathrm{~m}$ depth) and space in the section north of the Faroes. 

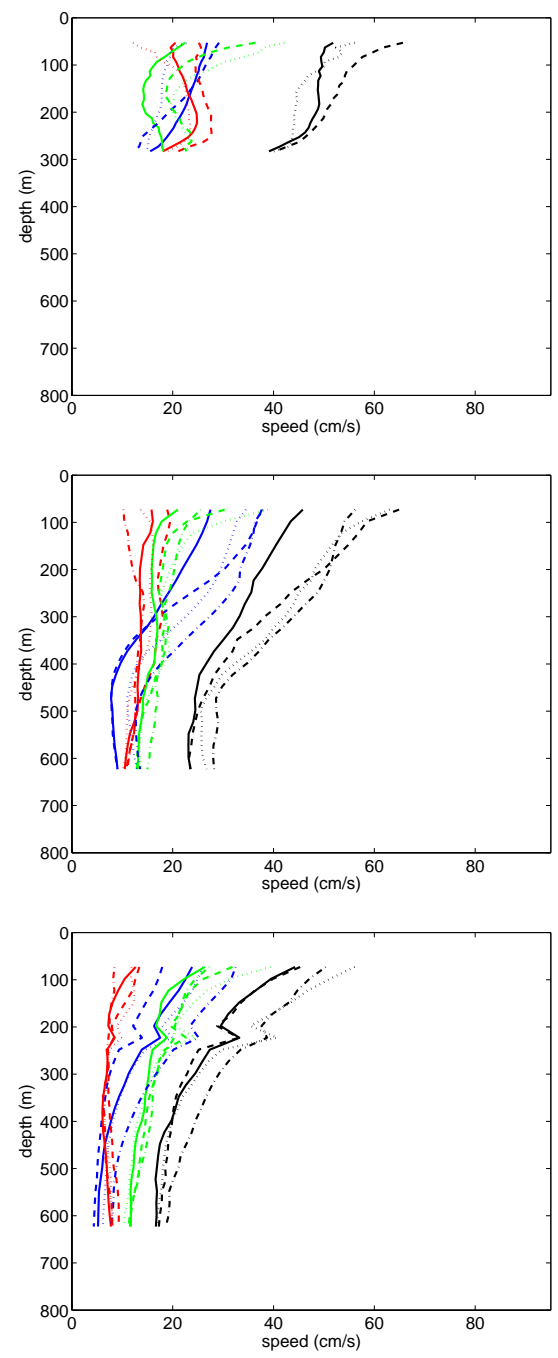

Fig. 5. Vertical profiles of 3 months averaged daily maximum speed for total currents (black), mean residual flow (blue), surge component (green) and tide (red) at locations NA, NB and NC from top to bottom. Continuous (-) line stands for average over JuneSeptember, dashed (- -) line stands for average over SeptemberDecember, dotted (...) line stands for average over DecemberMarch and dash-dotted (-.-.) line stands for average over MarchJune.

where their amplitudes are comparable to the semi-diurnal ones or even larger (Fig. 7). The dominant constituents are always aligned with the topography, which suggests that there may be an energy leakage between the diurnal and semi-diurnal co-aligned components. This is not investigated.

\subsubsection{Mean Residual Flow and Surge Component}

In the FBC the presence of a strong residual current was found (Fig. 8), flowing almost continuously over the period analysed along the $315^{\circ}$ direction (Fig. 9) steered by the bathymetry slope contours and is much stronger at depth,

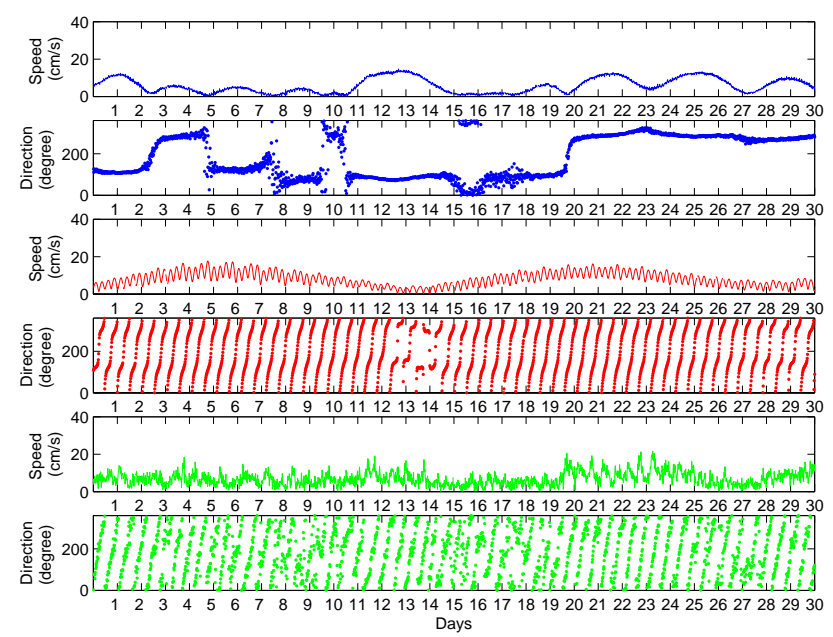

Fig. 6. From top to bottom speed $\left(\mathrm{cm} \mathrm{s}^{-1}\right)$ and direction (degrees) of mean-residual, tidal and surge components at location NB, $573 \mathrm{~m}$ depth (from 12 October 1997 to 10 November 1997).

though still evident near the surface suggesting a strong coherence throughout the water column.

The amplitude of the mean residual flow changes with depth, with high speed at the bottom (Fig. 9) and low speed at the surface. Strong mean residual flow at the bottom is in the northwest direction. This flow increases from about $500 \mathrm{~m}$ where tide and surge components are very small. The nearbottom mean residual current has peak values in the range $100 / 150 \mathrm{~cm} \mathrm{~s}^{-1}$ which is greater than the tidal and surge current together (Fig. 8). Besides, this current component has speed peaks with a period of 3 or 6 days of constant direction.

Superimposed on the low frequency mean residual flow there are the tide and surge, particularly the extremes of the surge component (high variation, but small speed). The periodicity of the surge component is just a few hours due to the interaction with the topography and storm events (Fig. 9).

The dominant direction of surges can be in phase or up to $90^{\circ}$ out of phase with the dominant direction of the mean residual flow and tide (Fig. 9). Peaks of about $30 / 50 \mathrm{~cm} \mathrm{~s}^{-1}$ in surface waters and $40 / 60 \mathrm{~cm} \mathrm{~s}^{-1}$ in deep waters were found.

\subsection{Section $\mathrm{S}$}

\subsubsection{Tidal Component}

In the FSC the largest values of tidal currents were found for the study area. The maximum value for the semi-major axis of $M_{2}$ was found at site SA in near-surface measurements (Fig. 10). This harmonic constituent decreases at corresponding levels from site SA to site SC along the section with increasing sea-floor depth (Fig. 10). At site SA the value of the semi-major axis for the dominant tidal harmonic $M_{2}$ increases with depth from the surface to about $150 \mathrm{~m}$ and then is almost constant and decreases only in bottom waters 
FA
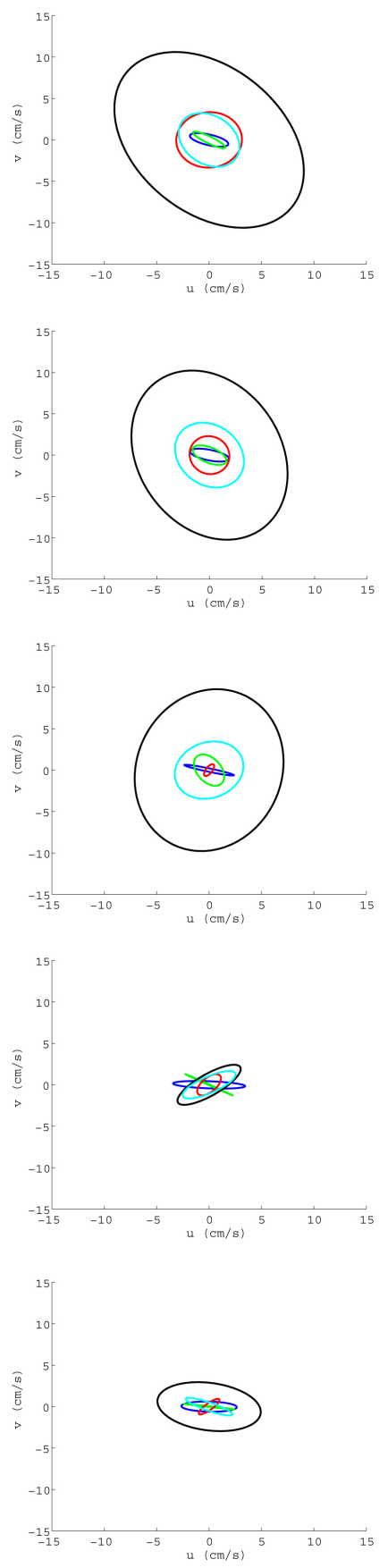

$F B$
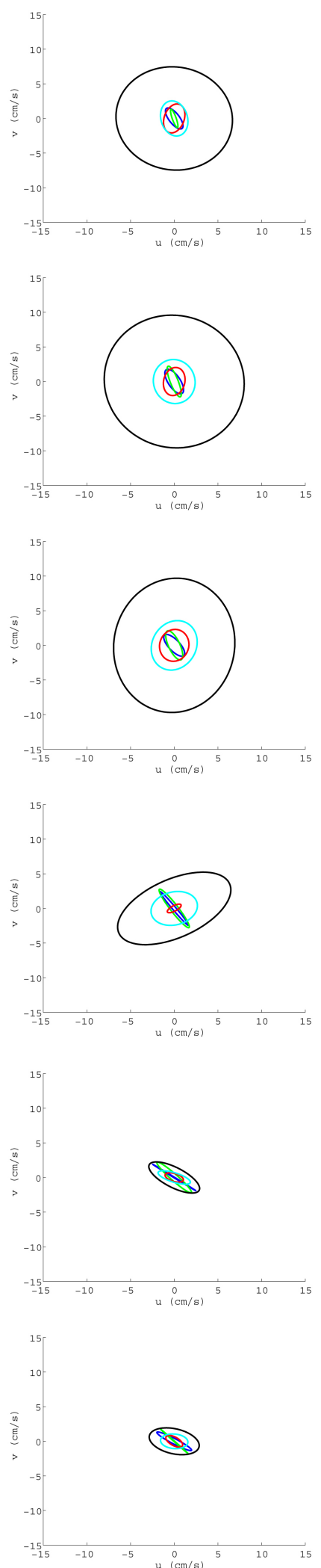

$F C$
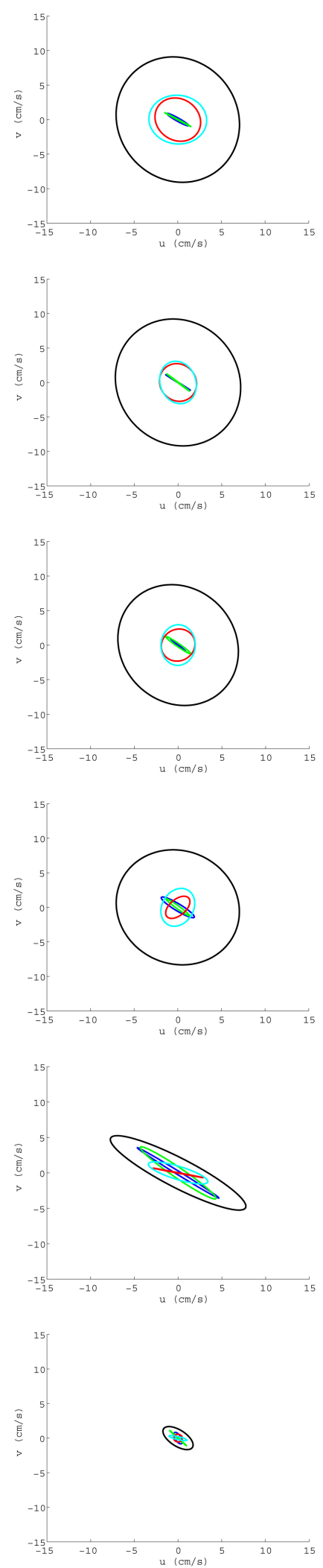

Fig. 7. Variation of tidal constituents ( $M_{2}$ black, $S_{2}$ cyan, $N_{2}$ red, $O_{1}$ blue and $K_{1}$ green) with depth (from top to bottom at about 220, 320, $420,520,620$, and $720 \mathrm{~m}$ depth) and space in the FBC section. 

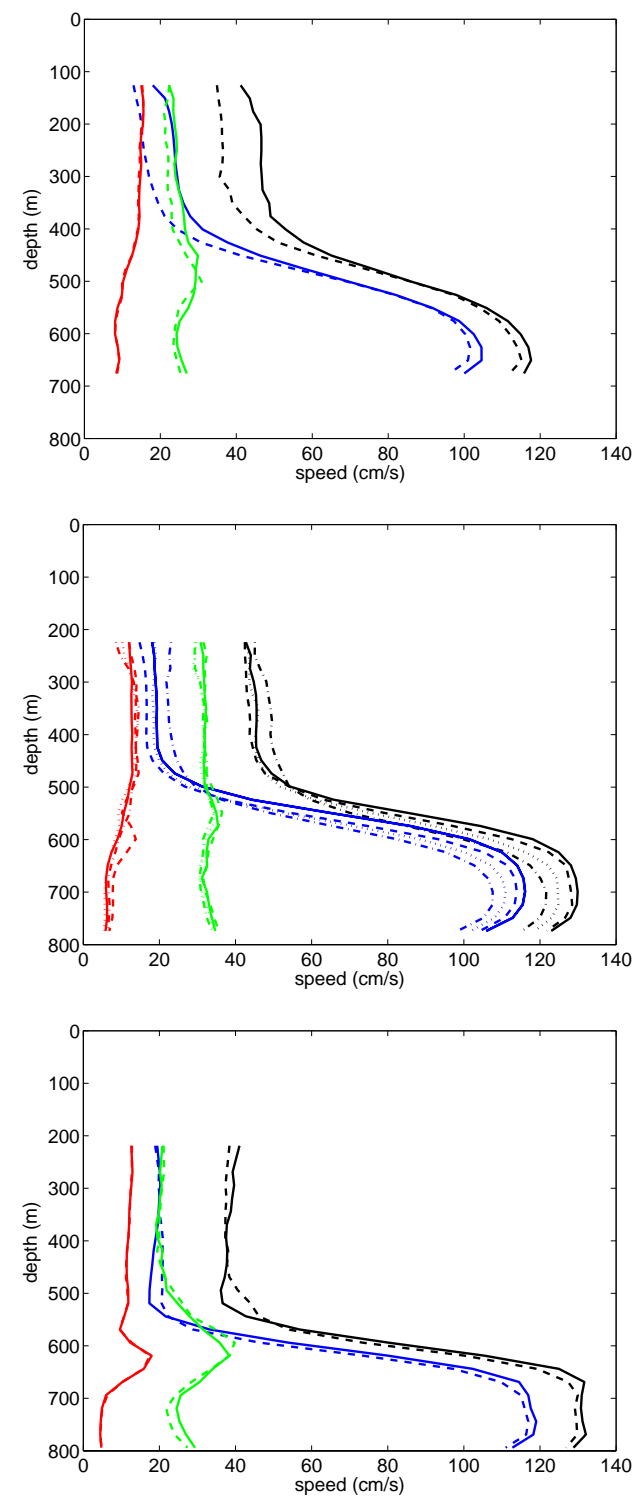

Fig. 8. Vertical profiles of 3 months averaged daily maximum speed for total currents (black), mean residual flow (blue), surge component (green) and tide (red) at locations FA, FB and FC from top to bottom. Continuous (-) line stands for average over JuneSeptember, dashed (- -) line stands for average over SeptemberDecember, dotted (...) line stands for average over DecemberMarch and dash-dotted (-.-.) line stands for average over MarchJune, only for location FB (mid plot). Instead continuous line stands for monthly averaged daily maxima over July-August and dashed line stands for monthly averaged daily maxima over AugustSeptember for locations FA and FC (top and bottom plots) where only 71 days long time series are available.

(Fig. 10). At location SB and SC a continuous increase of the semi-major axis is found from surface to deep waters, where it gets stable (Fig. 10).

The other analysed components are smaller than $M_{2}$ (Fig. 10). The harmonics $N_{2}, O_{1}$ and $K_{1}$ show very small

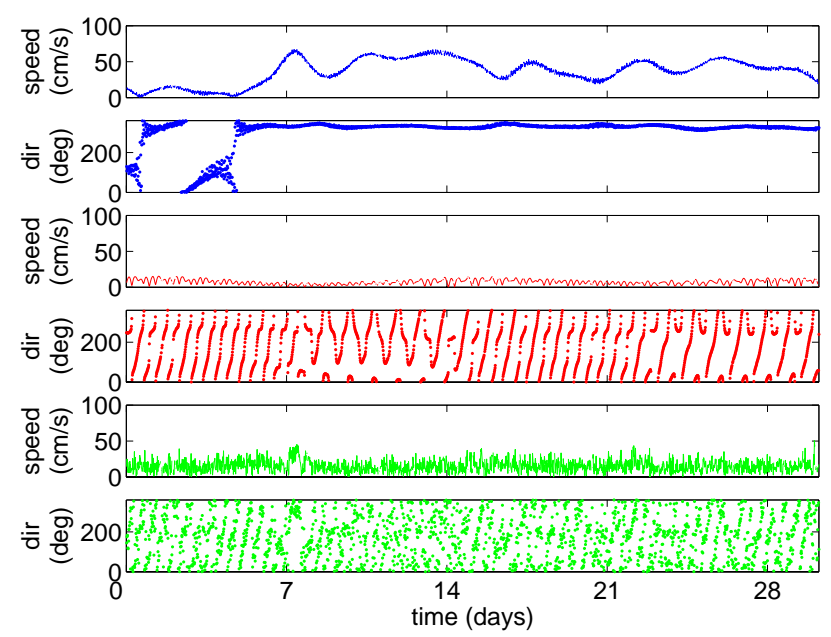

Fig. 9. Speed $\left(\mathrm{cm} \mathrm{s}^{-1}\right)$ and direction (degrees) of the mean-residual (blue), tidal (red), and surge (green) components at location FB, 524 m depth (from 14 November 1997 to 14 December 1997).

variations with depth and their inclinations suggest alongchannel flows (Fig. 10).

Tidal current ellipses exhibit relative uniformity in the vertical such that the tidal current near the bottom is comparable in amplitude to that found near the surface.

\subsubsection{Mean residual flow and surge component}

The mean residual flow decreases through depth while increasing along the section from SA to SC (Fig 11). It does not present a very stable or fixed directionality but in some months it shows a tendency of flowing along the $200^{\circ}$ direction (Fig. 12). In these locations the mean residual flow shows changes in direction when great changes in speed occur (Fig. 12). Periodicity of 3 to 6 days and peaks of $40 / 50 \mathrm{~cm} \mathrm{~s}^{-1}$ in surface waters (Fig. 12) and of $20 / 30 \mathrm{~cm} \mathrm{~s}^{-1}$ in near bottom measurements were found.

The surge component decreases slightly with depth but it is generally constant along the section at corresponding levels (Fig 11). It is smaller than the tide (the dominant component in this section) and mean residual flow (Fig 11). It shows a preferred direction of flow at SA $\left(30 / 90^{\circ}-210 / 270^{\circ}\right)$ from 48 to $148 \mathrm{~m}$, but not at SB (Fig. 12) or SC. Peaks of $80-130 \mathrm{~cm} \mathrm{~s}^{-1}$ in surface waters and $30-40 \mathrm{~cm} \mathrm{~s}^{-1}$ in deep waters were found.

\section{Discussion}

Some of the results showed above are similar to the ones obtained by the Faroese Fisheries Laboratory (Hansen et al., 1999a) that carried out tidal analyses in the same area, though different results particularly in surface measurements can be affected by the linear interpolation carried on in the present study before filtering. 
$S A$
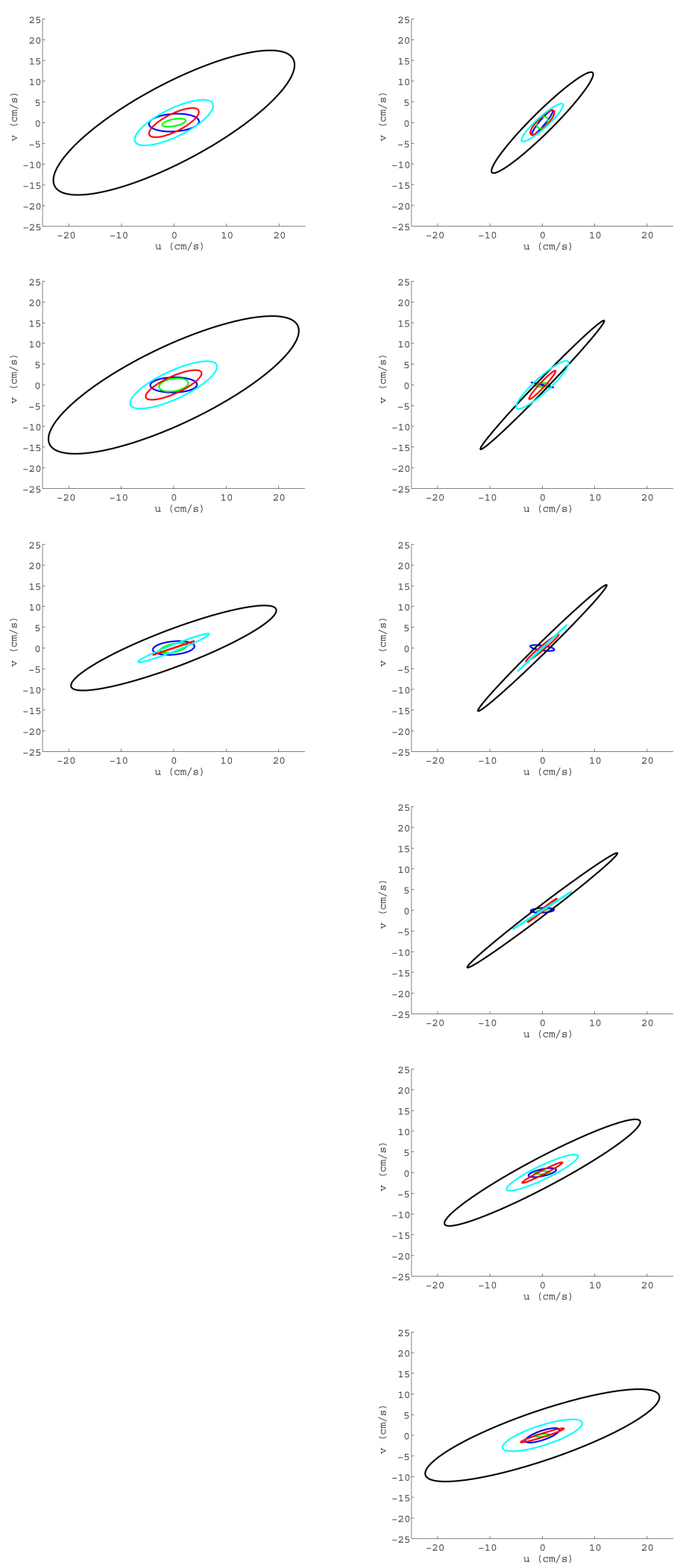

$S C$
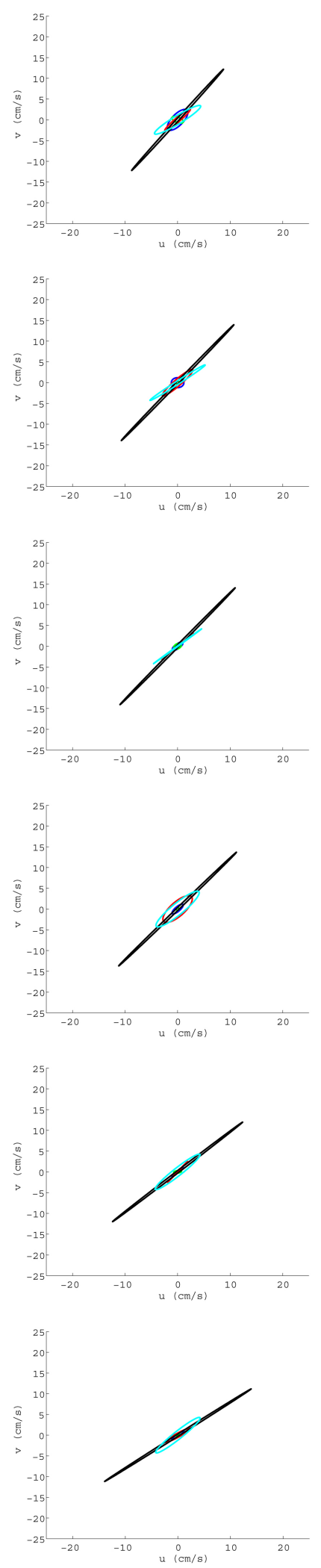

Fig. 10. Variation of tidal constituents ( $M_{2}$ black, $S_{2}$ cyan, $N_{2}$ red, $O_{1}$ blue and $K_{1}$ green) with depth (from top to bottom at about 220, 320, $420,520,620$, and $720 \mathrm{~m}$ depth) and space in the FSC section. 

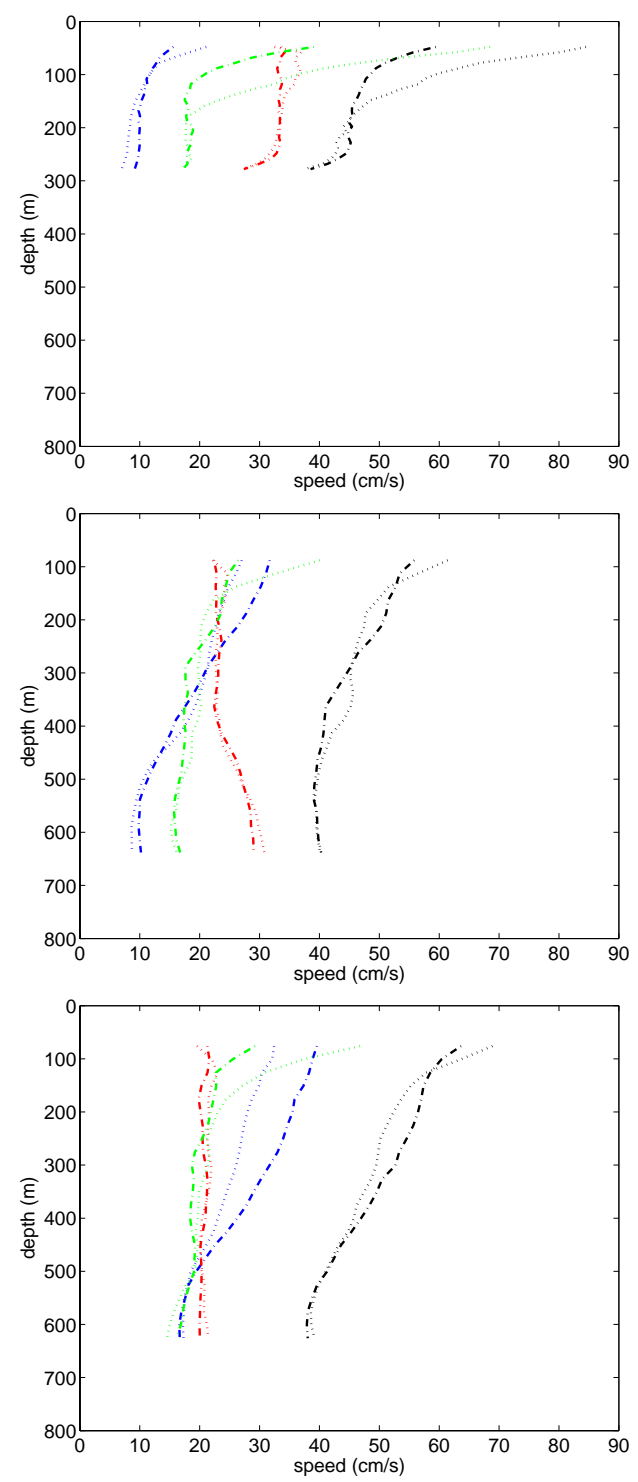

Fig. 11. Vertical profiles of 3 months averaged daily maximum speed for total currents (black), mean residual flow (blue), surge component (green) and tide (red) at locations SA, SB and SC from top to bottom. Continuous (-) line stands for average over JuneSeptember, dashed (- -) line stands for average over SeptemberDecember, dotted (...) line stands for average over DecemberMarch and dash-dotted (-.-.) line stands for average over MarchJune.

The spatial and vertical variations of tidal currents were analysed in a previous study (Larsen et al., 2000). The authors investigate the behavior of $M_{2}$ in the FBC and its regular variation with depth in sections $\mathrm{N}$ and $\mathrm{S}$. A clockwise rotation of the major-axis of the tidal ellipse with depth is seen more consistent north of the Faroes (as shown in Fig. 4). They propose a two layer system for the semi-diurnal constituents with a more complicated pattern for the diurnal ones. They also find that tidal ellipses generally rotate clockwise. This is confirmed by the results of the present study

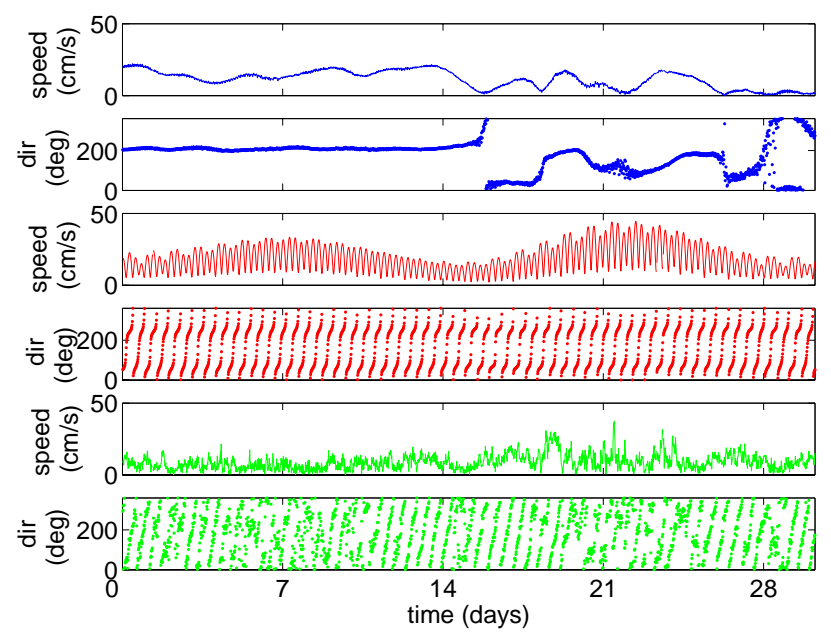

Fig. 12. From top to bottom speed $\left(\mathrm{cm} \mathrm{s}^{-1}\right)$ and direction (degrees) of mean-residual, tidal and surge components at location SB, $588 \mathrm{~m}$ depth (from 14 October 1998 to 12 November 1998).

particularly for the semi-diurnal constituents in sections $\mathrm{F}$ and $\mathrm{N}$.

The area north of the Faroe Islands is dominated by great changes in topography and bathymetry due to the Faroe Shelf and the warm and cold water masses that meet in this area. From south to north, the water depth is increasing and this feature strongly influences ocean currents. Also, the presence of an amphidrome north of the section makes tidal currents small at deployment NC.

Allen (1995) describes strong tidal currents dominating the velocity field in the IFF region. In the present study instead only at site NA is the tidal component larger than the surge and mean residual flow throughout the water column. At the other sites of section $\mathrm{N}$ the tide decreases with depth (Fig. 5). The surge is smaller than the mean-residual flow in near-surface waters, but in bottom waters it gets larger than the other two components. This discrepancy in results compared to the previous study is due to the fact that Allen (1995) made use of short time-series (only 29-day records) at only one depth $(252 \mathrm{~m})$.

Saunders (1990) found that in the FBC the tidal component $M_{2}$ is the dominant one and its amplitude is about $10 \mathrm{~cm} \mathrm{~s}^{-1}$ with larger speed in shallow waters (about $30 \mathrm{~cm} \mathrm{~s}^{-1}$ ). The results found here show that in this channel (1) the tide is smaller than the other two components at all depths (Fig.8) and (2) in deep measurements total currents are dominated by the mean-residual flow. The tide, surge and mean residual component are constant in the surfacemost measurements. The tide gets smaller through depth; the mean residual flow increases rapidly, while the surge does not show large changes. The oscillatory phenomenon of the mean residual flow with period of 3 to 6 days (Fig. 9) looks like a sort of pumping mechanism or flow rectification due to the presence of the slope and particularly to the nonlinear interaction of tides with bottom topography. This is 
in agreement with literature studies (Loder, 1980; Robinson, 1981; Wright and Loder, 1985; Tang and Tee, 1987; Loder et al., 1997; White and Bowyer, 1997; Shi et al., 2002) investigating the topographic rectification of tidal currents originating in nonlinearities that rectify the oscillatory tidal motion. This phenomenon occurs when two current components interact nonlinearly provided that both are in phase and thus correlate over a tidal cycle (Robinson, 1981; Clarke, 1991). As the continental shelf and slope form a large perturbation to the nearly constant-depth bottom topography, the deepsea ocean tide can be severely distorted over this topography (Clarke, 1991). The major factors influencing tidal rectification over sloping topography are described to be topographic features, density structures and flow interaction; these can all contribute to give rise to the phenomenon also in the FBC. This is described in the literature to play an important role all year-round as it is found in the present study.

In the FSC tides are larger than the surge and meanresidual flow, and dominate the velocity field at site SA (Fig.11). This can be due to the effect of the WyvilleThomson Ridge on the currents flowing parallel to the Scottish Shelf (Sherwin et al., 1999). At SB and SC the tidal component has magnitude larger than the surge from the seasurface to the sea-floor; the mean-residual component decreases with depth to become smaller than the other two components in bottom waters.

The semi-diurnal harmonics dominate throughout the water column. In general the clockwise component of these harmonics is larger than the anticlockwise component. Because of this structure the direction of the major axis of the tidal ellipse turns clockwise with depth (Figs. 4, 7, and 10) (Prandle, 1982). In contrast, the clockwise component is smaller than the anticlockwise component of the diurnal constituents, particularly in the FBC. As a result no rotation of the tidal ellipse with depth occurs.

The oscillatory period ( 3 to 6 days) that characterises the mean residual flow at almost all depths and deployments (Fig. 12) is similar to the results found by White and Bowyer (1997) for the shelf-edge current northwest of Ireland, where variability of $2-5$ days is seen. The authors find that the increase in mean current speed is due to the slope angle, and near-bottom currents are influenced by topographic steering.

The direction of the mean residual flow alternates between periods where it is constant for many days and 24-h periods during which it moves through $360^{\circ}$ at a constant rate (Fig. 6 and Fig. 12). This exactly matches the behavior of shelf waves as highlighted by Gordon and Huthnance (1987). Consequently, following Gordon and Huthnance (1987), we postulate that the long periods of constant current direction observed in Figs. 6 and 12 appear to be due to a quasi-steady response caused by long duration surface winds, whereas the single day current rotation anomaly is a response to storms lasting less than 12 hours (Gordon and Huthnance, 1987).

\section{Conclusion}

The results obtained in this work show that for the predominant tidal constituent $M_{2}$ the major axis of the ellipse is generally aligned with the topography and along-channel tidal currents are found.

The inclination of the semi-major axis of the most important constituents is strongly related to the bottom topography and the bathymetry of the analysed sections. In fact, the tidal ellipses for both diurnal and semi-diurnal tides and mean-residual flow are oriented approximately parallel to the local topography. Besides, in this region tidal currents give rise to strong residual currents due to nonlinear interactions with the bottom topography. In fact, where the distribution of tidal currents in deep waters differs significantly from the sea-surface one, the frictional effects and tidal rectification should be taken into consideration to explain the decrease of amplitude and change of inclination in bottom currents. As found in Lam et al. (2004) the effects above create an intensification of the along-channel flow that is bottom-trapped due to stratification.

The changes identified at about $500 \mathrm{~m}$ depth in section $\mathrm{F}$ for the semi-diurnal tidal constituents and mean residual flow can be due to a difference in water masses found above and below this level (as described in Sec. 2.2), thus indicating a two-layer structure for the FBC.

Largest tidal currents were found in the shallower water deployment in the FSC. Elsewhere the mean residual flow was found to be generally larger than the surge and tides and therefore the major component in determining total currents, and particularly the extremes of total currents.

The results show that the largest mean residual flow was found near sea-bed in the FBC deployments. Its 3 to 6 days periodicity is probably due to the effect of tidal rectification on shoaling topography. In this section, the amplitude of the mean residual component is such that in deep waters it dominates the flow field and masks the tide and surge.

The analysis of the directionality of the flow shows that in the passages of the Iceland-Scotland Ridge the currents follow the general pattern described in the published results. The main flow that comes from the North Atlantic Ocean trough the North Atlantic Current crosses the FBC going northwestward to flow through the Iceland-Faroe Gap and reach the region north of the Faroe Islands. Here the flow concentrates in the Faroe Current that splits into two branches: the first flows northward; the second, of interest here, crosses the FSC on the Faroe side. Part of this water goes through the Wyville-Thomson Ridge, in the southern part of the FSC, and the other part turns northwest to cross the FBC and return to the North Atlantic. In deep waters, the overflow comes from the Arctic Ocean, flows through the FSC enters the FBC and reaches the North Atlantic Ocean (Hansen and Østerhus, 2000) as North Atlantic Deep Water (NADW). 
Acknowledgements. This study has been partly sponsored by the University of Reading Research Endowment Trust Funds (RETF) and the Environmental Systems Science Centre (ESSC), University of Reading. A special thank to the Proudman Oceanographic Laboratory and particularly to P. Woodworth who provided the authors with TASK 2000 for the analysis of tides and to Z. Xu, who wrote the MATLAB software used in this study.

Topical Editor N. Pinardi thanks D. Prandle for his help in evaluating this paper.

\section{References}

Allen, J. T.: Subtidal and tidal currents in the vicinity of the IcelandFaroes Front, J. Atmos. Ocean. Tech., 12, 3, 567-588, 1995.

Bell, C., Vassie, J. M., and Woodworth, P. L.: POL-PSMSL Tidal Analysis Software Kit 2000 (TASK-2000), Proudman Oceanographic Laboratory, 2000.

Brink, K. H., Halpern, D., and Smith, R. L.: Circulation in the Peruvian upwelling system near $15^{\circ} \mathrm{S}$, J. Geophys. Res., 87, C7, 4036-4048, 1980.

Clarke, A. J.: The dynamics of barotropic tides over the Continental Shelf and slope (Review), in: Tidal Hydrodynamics, edited by: Parker, B. B., John Wiley and Sons Inc., New York, 79-108, 1991.

Dye, S. R., Bigg, G., and Turrel, W. R.: A time series of flow through the Faroe-Shetland Channel, WOCE Conference Halifax, Canada 24-29 May 1998.

Godfrey, J. S., Cresswell, G. R., and Boland, F. M.: Observations of low Richardson numbers and undercurrents near a front in the East Australian Current, J. Phys. Ocean., 10, 301-307, 1980.

Gordon, R. L. and Huthnance, J. M.: Storm-driven continental shelf waves over the Scottish continental shelf, Cont. Shelf Res., 9, 1015-1048, 1987.

Graff, J.: The distribution of current meter measurements due to unusual hydraulic phenomena, International Conference on Measuring Techniques of Hydraulics Phenomena in Offshore, Coastal and Inland Waters, Paper A3, London, England 9-11 April 1986.

Halpern, D.: Structure of a coastal upwelling during July 1973, Deep-Sea Res., 23, 495-508, 1976.

Halpern, D.: Observations of upper ocean currents at Domes Sites $\mathrm{A}, \mathrm{B}$, and $\mathrm{C}$ in the Tropical Central North Pacific Ocean during 1975 and 1976, Marine Geology and Oceanography of the Pacific Manganese Nodule Province, 43-82, 1979.

Halpern, D.: A Pacific Equatorial temperature section from $172^{\circ} \mathrm{E}$ to $100^{\circ} \mathrm{W}$ during winter and spring 1979 , Deep-Sea Res., 27A, 931-940, 1980.

Halpern, D.: Observations of annual El Niño thermal and flow variation at $0^{\circ}, 110^{\circ} \mathrm{W}$ and $0^{\circ}, 95^{\circ} \mathrm{W}$ during $1980-1985$. J. Geophys. Res., 92, C8, 8197-8212, 1987.

Halpern, D.: Comparison of upper Ocean VACM and VMCM observations in the Equatorial Pacific, J. Atmos. Ocean Techn., 4, 1, 84-93, 1987.

Halpern, D., Smith, R. L., and Mittelstaedt, E.: Cross-shelf circulation on the Continental Shelf off the northwest Africa during upwelling, J. Geophys. Res., 83, C3, 1366-1372, 1977.

Halpern, D., Smith, R. L., and Reed, R. K.: On the California Undercurrent over the Continental Slope off Oregon. J. Marine Res., 35, 4, 787-796, 1978.

Hansen, B. and Østerhus, S.: North Atlantic-Nordic Seas exchanges, Prog. Oceanog., 45, 109-208, 2000.
Hansen, B., Larsen, K. M. H., and Kristiansen, R.: ADCP deployments in Faroese Waters 1997-1999, Technical Report No. 9907, The Faroese Fisheries Laboratory, 1999.

Hansen, B., Jónsson, S., Lundberg, P., et al.: Exchanges of water, heat and salt between the Arctic Mediterranean and the World Ocean through the Iceland-Scotland Gap measured in the Nordic WOCE Programme, Poster at the World Ocean Circulation Experiment (WOCE) conference, Halifax, Canada, May 24-29 1998.

Hansen, B., Østerhus, S., Kristiansen, R., et al.: The Iceland-Faroe inflow of Atlantic Water to the Nordic Seas, CM1999/L:21, 1999.

Hansen, B., Jónsson, S., Quadfasel, D., et al.: Monitoring the Atlantic inflow and the Iceland-Scotland overflow, ASOF Meeting, Washington, November 2001.

Heathershaw, A. D.: Some observations of internal wave current fluctuations at the shelf-edge and their implications for sediment transport, Cont. Shelf Res., 4, 4, 484-493, 1985.

Jones, B. H. and Halpern, D.: Biological and physical aspects of a coastal upwelling event observed during March-April 1974 off northwest Africa. Deep-Sea Res., 28A, 71-81, 1981.

Lam, F-P. A., Maas, L. R. M., and Gerkema, T.: Spatial structure of tidal and residual currents as observed over the shelf break in the Bay of Biscay, Deep-Sea Res. Pt I, in press, 2004.

Larsen, K. M. H., Hansen, B., Kristiansen, R., et al.: Internal tides in the waters surrounding the Faroe Plateau, ICES 2000 Annual Conference, CM2000/L:09, 2000

Loder, J. W.: Topographic rectification of tidal currents on the sides of Georges Bank, J. Phys. Ocean., 10, 1399-1416, 1980.

Loder, J. W., Shen, Y., and Ridderinkhof, H.: Characterisation of three-dimensional lagrangian circulation associated with tidal rectification over a submarine bank, J. Phys. Ocean., 27, 1729$1742,1997$.

Østerhus, S., Hansen, B., Kristiansen, R., et al: The deep overflow through the Faroe Bank Channel, ICES 1999 Annual Science Conference, CM1999/L:19, 1999.

Pingree, R. D. and Mardell, G. T.: Slope turbulence, internal waves, and phytoplankton growth at the Celtic Sea Shelf-break. Philosophical Transcriptions of the Royal Society London, A382, 663-682, 1981.

Prandle, D.: The vertical structure of tidal currents and other oscillatory flows. Cont. Shelf. Res, 2, 191-207, 1982

Pugh, D. T.: Tides, surges and mean sea level, A handbook for engineers and scientists, John Wiley \& Sons, 1987.

Robinson, I. S.: Tidal vorticity and residual circulation, Deep-Sea Res. Pt I, 28, 3, 195-212, 1981.

Saunders, P. M: Near-Surface current measurements. Deep-Sea Res., 23, 249-257, 1976.

Saunders, P. M.: Cold outflow from the Faroe-Bank Channel, J. Phys. Ocean., 20, 1, 29-43, 1990.

Sherwin, T. J.: Evidence of a deep internal tide in the FaroeShetland Channel, in: Tidal Hydrodynamics, edited by: Parker, B. B., John Wiley \& Sons Inc., New York, 469-488, 1991.

Sherwin, T. J. and Jeans, D. R. G.: Offshore technology report: An investigation of mesoscale and internal wave activity in the Faroe-Shetland Channel, Health and Safety Executive, OTO97056, 1997.

Sherwin, T. J., Turrell, W. R., Jeans, D. R. G., et al.: Eddies and a mesoscale deflection of the slope current in the Faroe-Shetland Chennel, Deep-Sea Res Pt I, 46, 415-438, 1999.

Shi, M., Chen, C., Xu, Q., et al.: The role of Qiongzhou Strait in the seasonal variation of the south China Sea circulation. J. Phys. 
Ocean., 32, 103-121, 2002.

Simonsen, K.: Tides and tidal simulation in the area around the Faroe Islands, Nansen Environmental and Remote Sensing Center, Technical Report No. 166, 1999.

Tang, Y. and Tee, K. T: Effect of mean and tidal current interaction on the tidally induced residual current, J. Phys. Ocean., 17, 215230, 1987.
White, M. and Bowyer, P.: The shelf-edge current north-west of Ireland, Ann. Geophys., 15, 1076-1083, 1997,

Sref-ID1432-0576/ag/1997-15-1076.

Wright, D. G. and Loder, J. W.: A depth-dependent study of topographic rectification of tidal currents, Geophys. Astro. Fluid, 31, 169-220, 1985.

$\mathrm{Xu}, \mathrm{Z}$.: Ellipse parameters conversion and velocity profiles for tidal currents in Matlab, documentation and programs available at http://sea-mat.whoi.edu/, 2000. 